\title{
The increasing prevalence of myopia and high myopia among high school students in Fenghua city, eastern China: a 15-year population-based survey
}

Min Chen ${ }^{1,2}$, Aimin $\mathrm{Wu}^{3}$, Lina Zhang ${ }^{1,4}$, Wei Wang ${ }^{1,2}$, Xinyi Chen ${ }^{1,2}$, Xiaoning $\mathrm{Yu}^{1,2}$ and Kaijun Wang ${ }^{1,2^{*}}$

\begin{abstract}
Background: Myopia is the leading cause of preventable blindness in children and young adults. Multiple epidemiological studies have confirmed a high prevalence of myopia in Asian countries. However, fewer longitudinal studies have been performed to evaluate the secular changes in the prevalence of myopia, especially high myopia in China. In the present study, we investigated trends in the prevalence of myopia among high school students in Fenghua city, eastern China, from 2001 to 2015.

Methods: This was a population-based, retrospective study. Data were collected among 43,858 third-year high school students. Noncycloplegic autorefraction was used to determine refractive error, which was defined as low myopia, moderate myopia, high myopia and very high myopia according to the spherical equivalent from the worse eye of each participant. The prevalence of myopia was calculated and the annual percentage change (APC) was used to quantify the time trends. All analyses were conducted using the SPSS, Stata and Graphpad Prism software.

Results: From 2001 to 2015, the prevalence of overall myopia increased from $79.5 \%$ to $87.7 \%$ (APC =0.59\%), with a significant increase of moderate myopia ( $38.8 \%$ to $45.7 \%$, APC $=0.78 \%$ ), high myopia ( $7.9 \%$ to $16.6 \%$, APC $=5.48 \%$ ) and very high myopia $(0.08 \%$ to $0.92 \%, A P C=14.59 \%)$, while the prevalence of low myopia decreased from $32.7 \%$ to $24.4 \%$ (APC $=-1.73 \%$ ). High myopia and very high myopia contributed the major part of the increasing trend of myopia prevalence (contribution rate $27.00 \%$ and $69.07 \%$, respectively).

Conclusions: During the 15-year period, there was a remarkable increase in the prevalence of high and very high myopia among high school students, which might become a serious public health problem in China for the next few decades.
\end{abstract}

Keywords: Epidemiology, Myopia, High myopia, Prevalence, High school student

\footnotetext{
* Correspondence: ze_wkj@zju.edu.cn

${ }^{1}$ Eye Center, the 2nd Affiliated Hospital, Medical College of Zhejiang University, Hangzhou, China

${ }^{2}$ Zhejiang Provincial Key Lab of Ophthalmology, Hangzhou, China

Full list of author information is available at the end of the article
}

(c) The Author(s). 2018 Open Access This article is distributed under the terms of the Creative Commons Attribution 4.0 International License (http://creativecommons.org/licenses/by/4.0/), which permits unrestricted use, distribution, and reproduction in any medium, provided you give appropriate credit to the original author(s) and the source, provide a link to the Creative Commons license, and indicate if changes were made. The Creative Commons Public Domain Dedication waiver (http://creativecommons.org/publicdomain/zero/1.0/) applies to the data made available in this article, unless otherwise stated. 


\section{Background}

Myopia is the leading cause of preventable blindness in children and young adults [1]. Recently, there has been growing evidence that the prevalence of myopia has increased rapidly in many parts of the world, especially in East and South Asia [2, 3]. For example, the prevalence of myopia were $96.5 \%$ in 19-year-old males in Seoul in 2010 [4]. In Taiwan, the prevalence of myopia in male military conscripts aged 18 to 24 years was $86.1 \%$ in 2010-2011 [5]. In China, the prevalence of myopia was 95.5\% in university students in Shanghai [6], 84.6\% in school children in Shandong [7]. Dramatic increases were also seen in other parts of the world $[8,9]$. It has been estimated that myopia will affect nearly 5 billion people by the year 2050 and become a major public health challenge [10].

Due to its high prevalence in China, people tend to ignore the importance of myopia prevention and control, especially in high and very high myopia. High myopia-associated complications such as retinal detachment, macular lesions, peripapillary deformation and myopia choroidal neovascularization may lead to severe and irreversible visual loss [11]. Related complications of high myopia will become one of the main causes of visual impairment in the next few decades in the world $[12,13]$. Jung et al. reported that the prevalence of high myopia was $21.6 \%$ in 19-year-old males in Seoul in 2010 [4]. In Singapore, the prevalence of high myopia slightly increased from $13.1 \%$ (1996-1997) to $14.7 \%$ (2009-2010) in young male subjects [14].

In the present study, we analyzed longitudinal data obtained from high school students in Fenghua city, eastern China from 2001 to 2015, to evaluate secular trends in myopia prevalence, especially in high and very high myopia, to provide guidance for the future management of myopia in China.

\section{Methods}

\section{Study population}

This retrospective study was conducted from 2001 to 2015, in Fenghua city, a county-level city located in the eastern part of Zhejiang province, China. There were seven high schools in this city. As part of the physical examination that students undertake for the National College Entrance Examination, the refractive status of all the third-year students (grade 12) were routinely collected each year. Fenghua people's hospital was in charge of the physical examination in this district. All students were registered by name, gender, age, visual activity and refractive status. The database was kept by the hospital and we retrieved the data between 2001 and 2015 for analysis, with the official permission from the hospital. Ethical approval was obtained from the Medical College of Zhejiang University and
Fenghua people's hospital Ethics Review Board. The study adhered to the tenets of the Declaration of Helsinki.

\section{Eye examination}

Eye examination was conducted by two experienced ophthalmologists and two qualified optometrists from the ophthalmology department of Fenghua people's hospital. All subjects underwent a measurement of uncorrected visual acuity (UCVA) at $5 \mathrm{~m}$ (Standard Logarithmic Visual Acuity E chart). If UCVA was lower than 5.0, best-corrected visual acuity (BCVA) was measured with subjective refraction. A slit lamp examination was performed to exclude opacity of optical media.

\section{Refraction error measurement}

Refractive error (RE) of each subject was measured by automatic refractometer (AR-600; Nidek Ltd., Tokyo, Japan) without cycloplegia. The spherical equivalent refraction (SER) was calculated by the addition of the spherical refraction and half the cylindrical refraction. The baseline SER from the worse eye of each student was used for analysis, which was divided in to five groups: non-myopia (SER less than $-0.5 \mathrm{D}$ ), low myopia (SER between $-0.5 \mathrm{D}$ and $-3.0 \mathrm{D}$ ), moderate myopia (SER between $-3.0 \mathrm{D}$ and $-6.0 \mathrm{D}$ ), high myopia (SER greater than $-6.0 \mathrm{D}$ ), and very high myopia (SER greater than $-10.0 \mathrm{D})$.

\section{Meta-analysis}

A meta-analysis was performed to evaluate myopia prevalence among young adults. A comprehensive literature search was conducted in PubMed and web of science covering publications up to December 2, 2017 by two independent authors, using the following key words ("myopia" OR "refractive error" OR "vision disorder") AND ("prevalence" OR "epidemiology" OR "incidence") AND ("young adults" OR "students"). Articles were selected based on title, abstract and full texts. The major inclusion criteria for this study were mentioning visual disorders and myopia prevalence among 16 to 39 years old young adults, and exclusion criteria were lack of reference to the prevalence of visual disorders, unrelated studies, and low quality of articles. The methodological quality evaluation of eligible studies was based on the following factors: specific diagnostic criteria, clear refraction method and matched age group. Two authors (XN $\mathrm{Y}$ and $\mathrm{MC}$ ) independently review and extracted data form the eligible studies. The following information was extracted from each article: first author, publication date, region and ethnicity, gender composition, mean age, sample size, refraction method, myopia definition, prevalence of myopia and high myopia etc. Statistical analysis was conducted using Stata 12.0 software (Stata Corp., Texas, USA). A Q-statistic test was applied and $P<0.10$ 
was considered to be statistically significant. Besides, $\mathrm{I}^{2}$ value was used to evaluate the heterogeneity, with $>50 \%$ as high degree of heterogeneity [15]. When no significant heterogeneity was observed among studies, the summary was pooled by using the fixed-effects model. Otherwise, the random-effects model was applied instead [16, 17]. Egger's linear regression test [18] and Begg's funnel plot [19] were used to assess the Potential publication bias.

\section{Statistical analysis}

Median [interquartile range (IQR)] and percentage were reported in the descriptive analyses for the continuous variables and the categorical variables, respectively. Myopia prevalence was calculated for fifteen 1-year time intervals from 2001 to 2015. Chi-squared test was used to compare the differences in myopia prevalence between males and females. The annual percentage change (APC) for myopia prevalence was used to quantify the time trends $[20,21]$. A regression line was fitted to the natural logarithm of the rates, $y=\alpha+\beta x+\varepsilon$, where $y=$ $\ln$ (rate) and $x=$ calender year, and then the APC was calculated as $100 \times\left(e^{\beta}-1\right)$. We also calculated the relative contributions for rate changes which provide us for determining the contributions from different kinds of myopia made to the overall trends [22]. All analyses (except when noted) were performed using SPSS statistics 22.0 (SPSS Inc., Chicago, Illinois, USA) and Graphpad Prism software, version 5.0 (Graphpad software Inc., SanDiego, CA, USA). A $P$ value of less than 0.05 was considered statistically significant.

\section{Results}

Characteristics of the study population

Basic characteristics of the study population were summarized in Table 1. A total of 43,858 high school students were enrolled from 2001 to 2015, including 21,843 (49.8\%) males and 22,015 (50.2\%) females. Those who had a history of traumas, eye diseases or refractive surgeries were excluded from the analysis. The average age of the subjects was $18.46 \pm 0.69$ years old.

\section{Changes in refractive error}

During the 15 years period, the mean SER significantly increased both in the right eye (from $-2.5 \pm 2.0 \mathrm{D}$ to -3.4 $\pm 2.3 \mathrm{D}$ ) and in the left eye (from $-2.4 \pm 2.0 \mathrm{D}$ to $-3.2 \pm$ 2.3D). Spearman's correlation analysis indicated that the refractive error (RE) was closely related between the right and left eyes (Table 2). Representative results presented in our study were from the worse eye of each subject.

\section{Prevalence of myopia}

From 2001 to 2015, the prevalence of overall myopia increased from $79.5 \%$ to $87.7 \%(P<0.05$, Fig. 1$)$. Compared between the five groups, the prevalence of non-myopia ( $20.5 \%$ to $12.4 \%$ ) and low myopia (32.7\% to $24.4 \%)$ significantly decreased, with a significant increase in the prevalence of moderate myopia ( $38.8 \%$ to $45.7 \%$ ), high myopia (7.9\% to $16.6 \%$ ) and very high myopia $(0.08 \%$ to $0.92 \%)$.

Fig 2 and Table 3 showed the time trend of myopia prevalence in each subgroup during 2001 to 2015. The annual percent change (APC) was $0.59 \%$ (95\%CI: 0.41 to

Table 1 Basic characteristics of the study population and difference in myopia prevalence between females and males in Fenghua city, eastern China, 2001 to 2015

\begin{tabular}{|c|c|c|c|c|c|c|c|}
\hline Year & $\mathrm{N}(\%)$ & Age & $\begin{array}{l}\text { Gender } \\
\text { Female/Male }\end{array}$ & $\begin{array}{l}\text { Myopia prevalence } \\
\text { Female/Male }\end{array}$ & OR & $95 \% \mathrm{Cl}$ & $P$ value \\
\hline 2001 & 2418 & $18.50 \pm 0.65$ & $1084 / 1334$ & $81.1 / 78.3$ & 1.19 & 0.98 to 1.46 & 0.087 \\
\hline 2002 & 2324 & $18.52 \pm 0.59$ & $997 / 1327$ & 86.0/81.8 & 1.37 & 1.09 to 1.71 & 0.007 \\
\hline 2003 & 2462 & $18.51 \pm 0.64$ & $1062 / 1400$ & $88.7 / 79.4$ & 2.04 & 1.62 to 2.57 & 0.000 \\
\hline 2004 & 2654 & $18.61 \pm 0.68$ & $1247 / 1407$ & $87.7 / 79.0$ & 1.90 & 1.53 to 2.35 & 0.000 \\
\hline 2005 & 3072 & $18.48 \pm 0.72$ & $1436 / 1636$ & $85.7 / 78.2$ & 1.68 & 1.39 to 2.02 & 0.000 \\
\hline 2006 & 2974 & $18.49 \pm 0.73$ & $1454 / 1520$ & 85.8/78.2 & 1.69 & 1.40 to 2.05 & 0.000 \\
\hline 2007 & 3014 & $18.34 \pm 0.57$ & $1497 / 1517$ & 89.0/78.8 & 2.19 & 1.79 to 2.69 & 0.000 \\
\hline 2008 & 3055 & $18.64 \pm 0.74$ & $1481 / 1574$ & $89.5 / 80.7$ & 2.03 & 1.65 to 2.50 & 0.000 \\
\hline 2009 & 2930 & $18.56 \pm 0.73$ & $1517 / 1413$ & 89.0/81.0 & 1.89 & 1.54 to 2.33 & 0.000 \\
\hline 2010 & 3276 & $18.46 \pm 0.70$ & $1801 / 1475$ & $89.7 / 84.0$ & 1.65 & 1.35 to 2.03 & 0.000 \\
\hline 2011 & 3079 & $18.51 \pm 0.69$ & $1655 / 1424$ & $89.1 / 82.9$ & 1.69 & 1.38 to 2.09 & 0.000 \\
\hline 2012 & 3283 & $18.46 \pm 0.71$ & $1794 / 1489$ & $90.1 / 82.2$ & 1.97 & 1.60 to 2.41 & 0.000 \\
\hline 2013 & 3234 & $18.41 \pm 0.65$ & $1755 / 1479$ & 88.8/83.0 & 1.62 & 1.32 to 1.98 & 0.000 \\
\hline 2014 & 3151 & $18.39 \pm 0.62$ & $1671 / 1480$ & $90.9 / 85.3$ & 1.72 & 1.38 to 2.14 & 0.000 \\
\hline 2015 & 2932 & $18.31 \pm 0.60$ & 1564/1368 & $90.8 / 84.1$ & 1.87 & 1.49 to 2.34 & 0.000 \\
\hline
\end{tabular}


Table 2 Correlation of refractive error between the right and left eyes

\begin{tabular}{|c|c|c|c|c|c|c|}
\hline \multirow[t]{2}{*}{ Year } & \multicolumn{2}{|l|}{ Right } & \multicolumn{2}{|l|}{ Left } & \multirow[t]{2}{*}{$P$ value $^{a}$} & \multirow[t]{2}{*}{ Spearman } \\
\hline & Mean \pm SD & Median (IQR) & Mean \pm SD & Median (IQR) & & \\
\hline 2001 & $-2.5 \pm 2.0$ & $-3.0(-4.0,-2.0)$ & $-2.4 \pm 2.0$ & $-3.0(-4.0,-2.0)$ & 0.021 & 0.90 \\
\hline 2002 & $-2.7 \pm 2.0$ & $-3.0(-4.0,-2.0)$ & $-2.6 \pm 2.0$ & $-3.0(-4.0,-2.0)$ & 0.020 & 0.89 \\
\hline 2003 & $-2.8 \pm 2.0$ & $-3.0(-4.5,-2.0)$ & $-2.7 \pm 2.0$ & $-3.0(-4.0,-2.0)$ & 0.011 & 0.89 \\
\hline 2004 & $-2.8 \pm 2.0$ & $-3.0(-4.0,-2.0)$ & $-2.7 \pm 2.0$ & $-3.0(-4.0,-2.0)$ & 0.006 & 0.90 \\
\hline 2005 & $-2.6 \pm 2.1$ & $-3.0(-4.0,-2.0)$ & $-2.5 \pm 2.1$ & $-3.0(-4.0,-2.0)$ & 0.004 & 0.90 \\
\hline 2006 & $-2.7 \pm 2.0$ & $-3.0(-4.0,-2.0)$ & $-2.6 \pm 2.0$ & $-3.0(-4.0,-2.0)$ & 0.010 & 0.92 \\
\hline 2007 & $-2.9 \pm 2.0$ & $-3.5(-4.0,-2.0)$ & $-2.8 \pm 2.0$ & $-3.0(-4.0,-2.0)$ & 0.037 & 0.91 \\
\hline 2008 & $-3.0 \pm 2.1$ & $-3.5(-4.5,-2.0)$ & $-2.9 \pm 2.1$ & $-3.5(-4.5,-2.0)$ & 0.007 & 0.92 \\
\hline 2009 & $-3.1 \pm 2.2$ & $-3.5(-5.0,-2.0)$ & $-3.0 \pm 2.2$ & $-3.5(-4.5,-2.0)$ & 0.022 & 0.93 \\
\hline 2010 & $-3.1 \pm 2.2$ & $-3.5(-5.0,-2.25)$ & $-3.0 \pm 2.2$ & $-3.5(-4.5,-2.0)$ & 0.012 & 0.90 \\
\hline 2011 & $-3.2 \pm 2.1$ & $-3.5(-5.0,-2.5)$ & $-3.0 \pm 2.2$ & $-3.5(-4.75,-2.0)$ & 0.011 & 0.92 \\
\hline 2012 & $-3.2 \pm 2.2$ & $-3.5(-5.0,-2.5)$ & $-3.1 \pm 2.2$ & $-3.5(-5.0,-2.0)$ & 0.007 & 0.93 \\
\hline 2013 & $-3.2 \pm 2.1$ & $-3.5(-5.0,-2.5)$ & $-3.1 \pm 2.2$ & $-3.5(-5.0,-2.25)$ & 0.010 & 0.91 \\
\hline 2014 & $-3.3 \pm 2.2$ & $-3.5(-5.0,-2.5)$ & $-3.1 \pm 2.2$ & $-3.5(-5.0,-2.25)$ & 0.006 & 0.91 \\
\hline 2015 & $-3.4 \pm 2.3$ & $-3.5(-5.0,-1.75)$ & $-3.2 \pm 2.3$ & $-3.25(-5.0,-1.5)$ & 0.000 & 0.93 \\
\hline
\end{tabular}

$R E$ refractive error, $I Q R$ interquartile range, ${ }^{a}$ Mann Whitney test

0.77, $P=0.000)$. Significant decreasing trend was observed in low myopia subgroup $(\mathrm{APC}=-1.73,95 \% \mathrm{CI}$ : -2.23 to $-1.24, P=0.000$ ), while significant increasing trend was found in moderate myopia $(\mathrm{APC}=0.78$, 95\%CI: 0.36 to $1.20, P=0.001$ ), high myopia $(\mathrm{APC}=$ 5.48, 95\%CI: 4.40 to $6.54, P=0.000$ ), especially in very high myopia $(\mathrm{APC}=14.59,95 \% \mathrm{CI}: 7.33$ to $22.34, P=$ 0.001 ). As shown in Table 4, high myopia (contribution rate $27.00 \%$ ) and very high myopia (contribution rate $69.07 \%$ ) contributed the major part of the increasing trend of myopia prevalence.

\section{Males versus females}

Compared between genders, the prevalence of overall myopia was higher in females than males (Chi-squared test,
$P<0.005$; except for 2001, $P=0.087$, Table 1, Fig. 3). From 2001 to 2015 , the prevalence of myopia increased $9.7 \%$ in female students $(81.1 \%$ to $90.8 \%$, mean $=88.1 \pm 2.6 \%$, $P<0.001)$ and $5.8 \%$ in male students $(78.3 \%$ to $84.1 \%$, mean $=81.1 \pm 2.4 \%, \mathrm{P}<0.001)$, respectively. The odds ratio (OR) was 1.87 (95\%CI: 1.49 to $2.34, P=0.000$ ) in 2015 .

\section{Meta-analysis of myopia prevalence}

A meta-analysis was conducted to evaluate myopia prevalence in young adults. The search strategy identified 125 unique articles, from which 12 full-text articles were retrieved for final review after screening titles and abstracts. Characteristics of the included studies were summarized and shown in Table 5. No significant

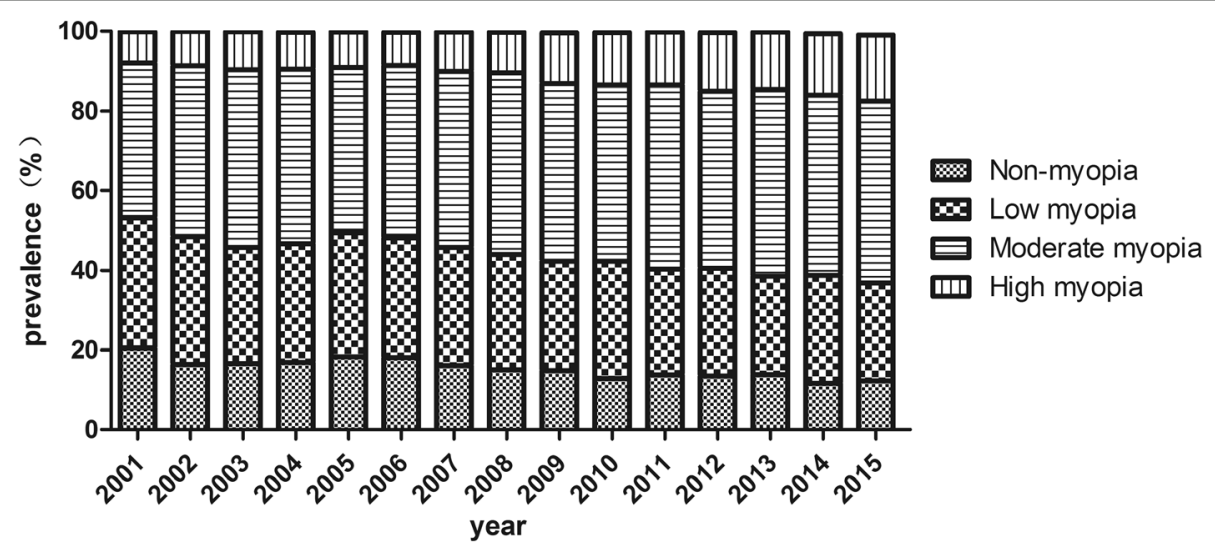

Fig. 1 Proportional distribution of refractive error among young adults in Fenghua city, eastern China, from 2001 to 2015 


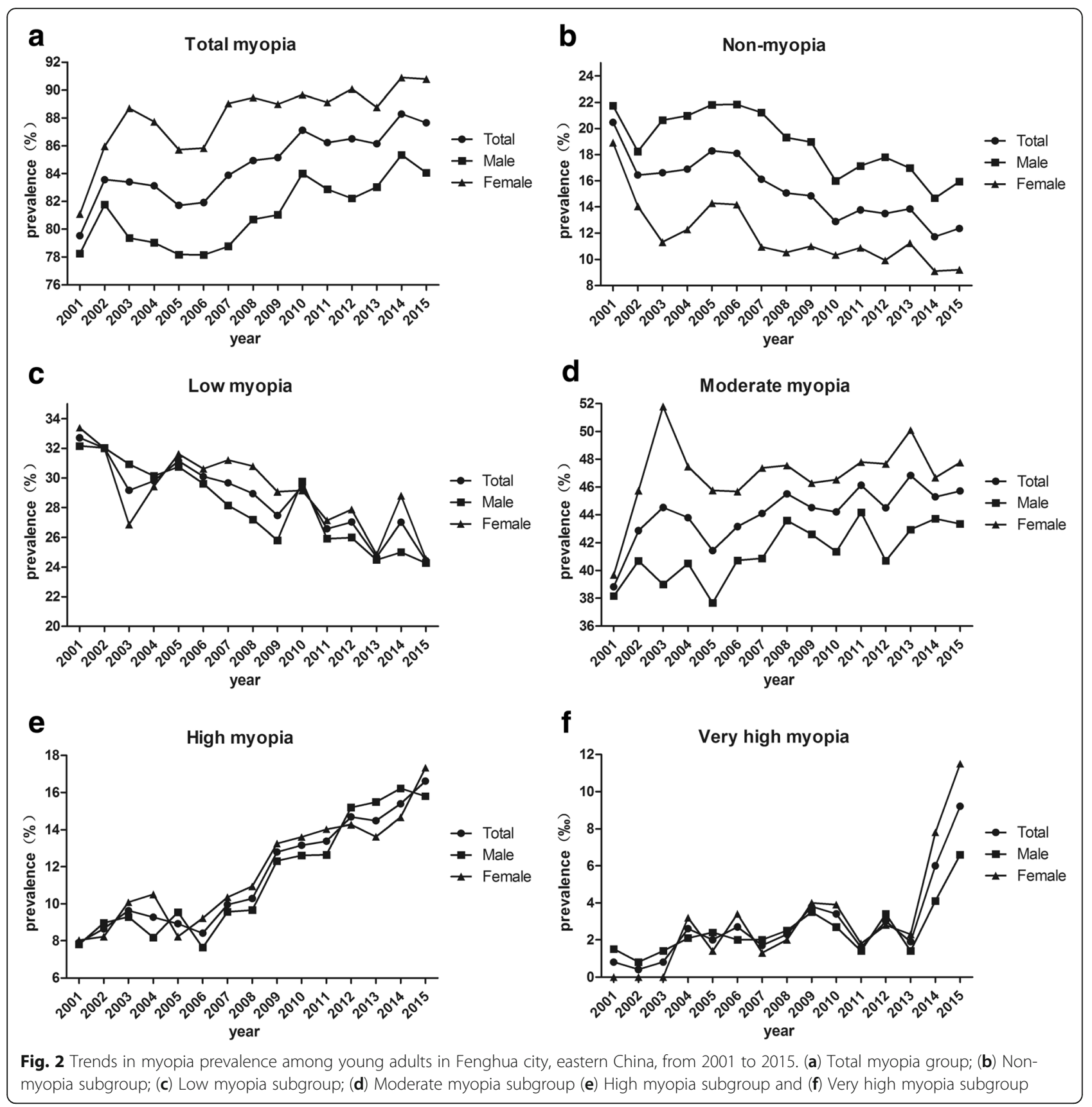

Table 3 Trends in myopia prevalence among high school students in Fenghua city, eastern China, during 2001 to 2015

\begin{tabular}{|c|c|c|c|c|c|c|c|}
\hline & \multicolumn{2}{|l|}{2001} & \multicolumn{2}{|l|}{2015} & \multirow[t]{2}{*}{ APC (\%) } & \multirow[t]{2}{*}{$95 \% \mathrm{Cl}$} & \multirow[t]{2}{*}{$P$ value } \\
\hline & $\bar{N}$ & Prevalence (\%) & $\overline{\mathrm{N}}$ & Prevalence (\%) & & & \\
\hline Total myopia & 1923 & 79.53 & 2570 & 87.65 & 0.59 & $0.41,0.77$ & 0.000 \\
\hline Low myopia & 791 & 32.71 & 716 & 24.42 & -1.73 & $-2.23,-1.24$ & 0.000 \\
\hline Moderate myopia & 939 & 38.83 & 1340 & 45.70 & 0.78 & $0.36,1.20$ & 0.001 \\
\hline High myopia & 191 & 7.90 & 487 & 16.61 & 5.48 & $4.40,6.54$ & 0.000 \\
\hline Very high myopia & 2 & 0.08 & 27 & 0.92 & 14.59 & $7.33,22,34$ & 0.001 \\
\hline
\end{tabular}

$\overline{A P C}$ annual percent change, $\mathrm{Cl}$, confidence interval, Annual percent change between 2001 and 2015 was calculated by the myopia prevalence 
Table 4 The relative contributions of decreasing and increasing trend of myopia prevalence among high school students in Fenghua city during 2001 to 2015

\begin{tabular}{lllll}
\hline & Decreasing trend & & \multicolumn{2}{l}{ Increasing trend } \\
\cline { 2 - 3 } \cline { 4 - 5 } & $\beta$ & Contribution rate (\%) & & Contribution rate (\%) \\
\hline Low myopia & -0.02 & 100 & 0.008 & 3.93 \\
Moderate myopia & & 0.053 & 27.00 \\
High myopia & & 0.136 & 69.07 \\
Very high myopia & & & \\
\hline
\end{tabular}

publication bias was found among the included studies (Begg's $P=0.23$, Egger's $P=0.34$ ). Sensitivity analysis showed that no individual study affected the pooled incidence, both in myopia and high myopia group. Forest plot for included studies showed the prevalence of myopia (Fig. 4 a, incidence $69.9,95 \% \mathrm{CI}=49.5-90.3 \%, \mathrm{I}^{2}=$ $100 \%, P=0.000$ ) and high myopia (Fig. $4 \mathrm{~b}$, incidence 11.6, $\left.95 \% \mathrm{CI}=7.6-15.6 \%, \mathrm{I}^{2}=99.9 \%, P=0.000\right)$ in the random-effects model (Additional files 1).

\section{Discussion}

Our study showed a remarkable increase in the prevalence of myopia among high school students in eastern China over a 15 -year period, especially high $(\mathrm{APC}=$
$5.48 \%)$ and very high myopia $(\mathrm{APC}=14.59 \%)$. Females were more likely to develop myopia than males.

During the past decades, multiple population-based surveys from different areas of the world have provided comparative data on the prevalence of myopia in young adults (Table 5, Fig. 4 a). In our study, the overall myopia prevalence in high school students increased from $79.5 \%$ in 2001 to $87.7 \%$ in 2015 . In Taiwan, the prevalence of myopia in 18-year-old children increased from 74\% in 1983 to 84\% in 2004 [23]. In Singapore, the overall myopia prevalence in young males increased from $79.2 \%$ in $1996-1997$ to $81.6 \%$ in $2009-2010$ [14]. In Korea, the prevalence of myopia and high myopia among young males was significantly higher in an urban
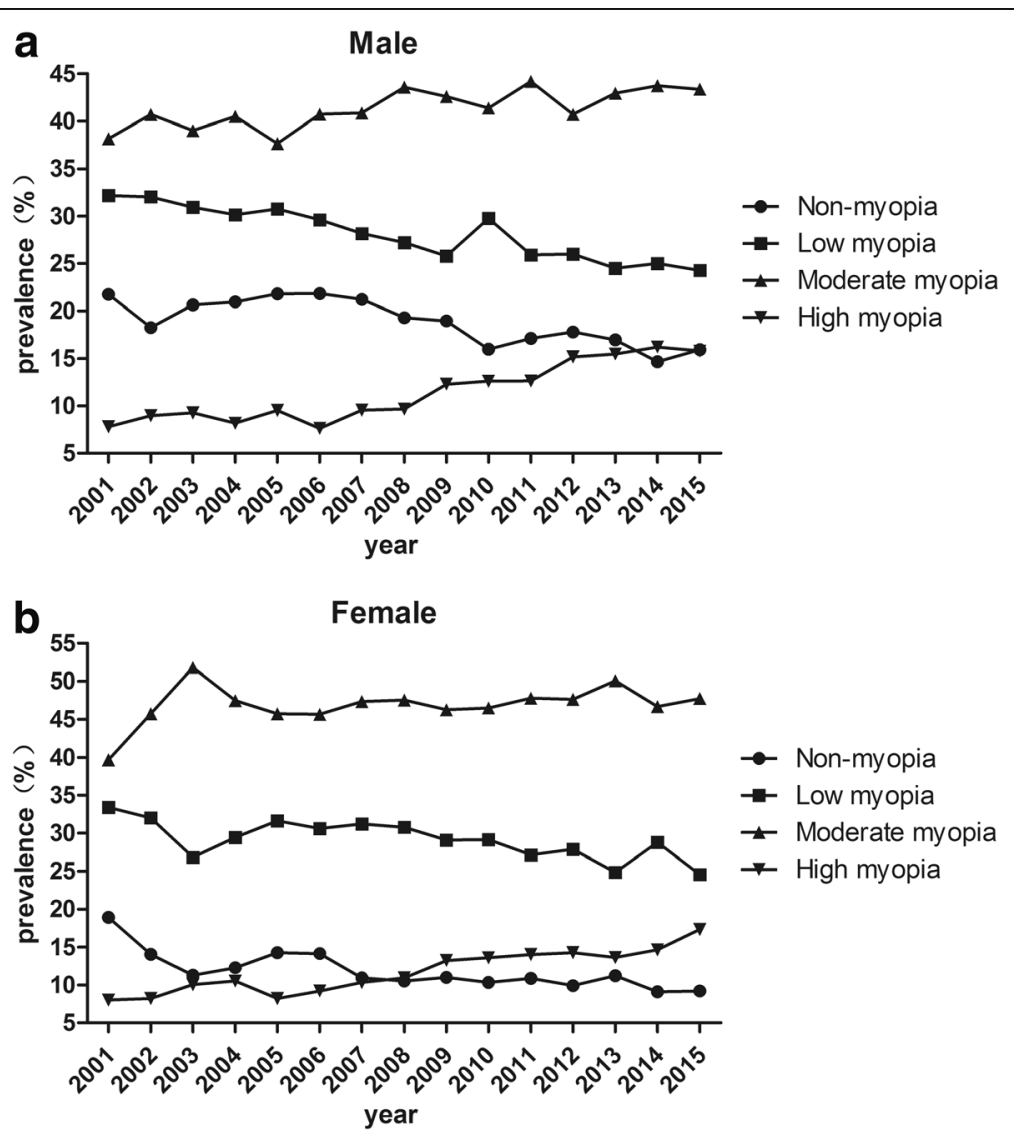

Fig. 3 The prevalence of myopia including subgroups in male (a) and female (b) subjects in Fenghua city, eastern China, from 2001 to 2015 
Table 5 Summary and meta-analysis of recent studies on myopia and high myopia prevalence among young adults

\begin{tabular}{|c|c|c|c|c|c|c|c|c|c|}
\hline \multirow[t]{2}{*}{ Author (Year) } & \multirow[t]{2}{*}{ Location } & \multirow{2}{*}{$\begin{array}{l}\text { Population- } \\
\text { based? }\end{array}$} & \multirow[t]{2}{*}{$\mathrm{N}$} & \multirow{2}{*}{$\begin{array}{l}\text { Refraction } \\
\text { method }\end{array}$} & \multirow{2}{*}{$\begin{array}{l}\text { Myopia } \\
\text { definition }\end{array}$} & \multirow{2}{*}{$\begin{array}{l}\text { Mean } \\
\text { Age }\end{array}$} & \multicolumn{2}{|c|}{ Prevalence (\%) } & \multirow[t]{2}{*}{ Ref } \\
\hline & & & & & & & Myopia & High myopia & \\
\hline Jung (2012) & Seoul, Korea & $\mathrm{No}^{\mathrm{a}}$ & 23,616 & CAR & $<-0.5 \mathrm{D}$ & 19 & 96.5 & 21.61 & Ref 8 \\
\hline Sun (2012) & Shanghai, China & Yes & 5083 & NCAR & $<-0.5 \mathrm{D}$ & 20 & 95.5 & 19.5 & Ref11 \\
\hline Lee (2013) & Taiwan, China & $\mathrm{No}^{\mathrm{a}}$ & 5145 & NCAR & $<-0.5 \mathrm{D}$ & 21.6 & 86.1 & NA & Ref 9 \\
\hline $\operatorname{Lin}(2004)$ & Taiwan, China & Yes & 45,345 & CAR & $<-0.25 D$ & 18 & 84 & 16 & Ref17 \\
\hline Lee (2013) & Jeju, Korea & $\mathrm{No}^{\mathrm{a}}$ & 2805 & CAR & $<-0.5 \mathrm{D}$ & 19 & 83.3 & 6.8 & Ref18 \\
\hline Koh (2014) & Singapore & $\mathrm{No}^{\mathrm{a}}$ & 28,908 & NCAR & $<-0.5 \mathrm{D}$ & 19.5 & 81.6 & 14.7 & Ref10 \\
\hline Wu (2013) & Shandong, China & Yes & 6364 & NCAR & $\leq-0.5 \mathrm{D}$ & 17 & 80 & 14 & Ref12 \\
\hline You (2014) & Beijing, China & Yes & 16,771 & NCAR & $\leq-0.5 \mathrm{D}$ & 18 & 74.2 & 1.8 & Ref19 \\
\hline Li (2017) & Beijing, China & Yes & 37,424 & CAR & $\leq-0.5 \mathrm{D}$ & 15.25 & 66.48 & 6.69 & Ref13 \\
\hline Matamoros (2015) & France & Yes & 100,429 & NCAR & $\leq-0.5 \mathrm{D}$ & 38.5 & 39.1 & 3.4 & Ref19 \\
\hline Dayan (2005) & Israel & Yes & 919,929 & NCAR & $\leq-0.5 \mathrm{D}$ & 17 & 28.3 & NA & Ref14 \\
\hline Mcknight (2014) & Western Australia & Yes & 1344 & CAR & $<-0.5 \mathrm{D}$ & 20.1 & 23.7 & NA & Ref21 \\
\hline Meta-analysis ${ }^{\mathrm{b}}$ & - & - & - & - & - & - & 70 (49-90) & $12(8-16)$ & - \\
\hline
\end{tabular}

${ }^{a}$ data from male conscripts; NA not available, Ref reference NCAR non-cycloplegic autorefraction, CAR cycloplegic autorefraction. ${ }^{\mathrm{b}}$ pooled prevalence and $95 \%$ confidence interval of myopia and high myopia by meta-analysis

population (96.5\% and $21.6 \%$ in Seoul) [4] than in a rural population $(83.3 \%$ and $6.8 \%$ in Jeju) [24], which indicated that environmental factors may play an important role in the development of myopia [24]. In contrast, the incidence of myopia in Western countries varies significantly between different ethnic groups, with a rate of $39.1 \%(2012-2013)$ in France [25], 72\% (2007-2008) in Canada [26], 23.7\% (2014) in Western Austria [27] and 33.1\% (1999-2004) in the United States [28]. In general, myopia prevalence among young adults in East Asia is much higher than in Western countries.

Another remarkable change shown by our survey was that the proportion of high myopia (7.9\% to $16.6 \%)$, especially very high myopia $(0.08 \%$ to $0.92 \%)$ significantly increased during a 15 -year period. Similar results have been reported previously (Table 5, Fig. 4 b). In the Taiwan study, the prevalence of high myopia among 18-year-old students increased from $10.9 \%$ in 1983 to $21 \%$ in 2000 . The highest prevalence of high myopia was in Seoul (21.61\% in 2012) [4], followed by Shanghai (19.5\% in 2012) [6], Zhejiang (15.4\% in 2014), Shandong (14\% in 2013) [7],Beijing (6.69\% in 2015) [29] and Jeju (6.8\% in 2013) [5]. A recent systematic review predict that by 2050 there will be 4758 million people with myopia (49.8\% of the world population) and 938 million people with high myopia ( $9.8 \%$ of the world population) [10]. It has been reported that high myopia is associated with several ocular disorders such as glaucoma, cataract, maculopathy, choroidal neovascularization, macular hole and retinal detachment [11]. The increasing prevalence of high myopia and very high myopia may therefore result in a series of associated complications and become a serious public health problem. Future prevention efforts should be strengthened to control the increasing prevalence of high and very high myopia.

The etiology of myopia still remains unclear. However, genetic and environmental factors are widely believed to play an important role [13]. Near work is one of the important environmental factors [30]. In China, the school system, especially the National College Entrance Examination is becoming more and more competitive. All students aged 16 to 18 years usually spend much time in study and expect to achieve high scores in this important examination. Lack of outdoor activity is very common in Chinese students. For example, $12.5 \%$ of students did not take part in any outdoor activity, and $11.2 \%$ of high school students did not participate in any physical education classes [31]. Associated factors, such as increasing educational pressures, higher school achievement, more near work and less time in sports activity, may contribute to the increasing prevalence of myopia [32]. Compared between genders, female students usually spend more time with reading and work-related issues, with less outdoor activities, making them more vulnerable to developing myopia [33]. A significantly higher prevalence of myopia in female subjects was observed in our survey, which was consistent with the results of previous studies $[6,34,35]$.

Our study has several strengths. First, this was a population-based large scale study including 43,858 participants of similar age, which provided the status of myopia prevalence in this age group. Second, this was a long time period survey, which described a secular change and time trend of myopia prevalence during the past 15 years. However, several methodological 


\begin{tabular}{|c|c|c|c|}
\hline \multirow[t]{16}{*}{ a } & \multicolumn{2}{|l|}{ Study ID } & Weight \% \\
\hline & Jung (2012) & $0.96(0.96,0.97)$ & 8.33 \\
\hline & Sun (2012) & $0.95(0.95,0.96)$ & 8.33 \\
\hline & Lee (2013) & - $\quad 0.86(0.85,0.87)$ & 8.33 \\
\hline & $\operatorname{Lin}(2004)$ & - $\quad 0.84(0.84,0.84)$ & 8.33 \\
\hline & Lee (2013) & - $\quad 0.83(0.82,0.85)$ & 8.33 \\
\hline & Koh (2014) & - $\quad 0.82(0.81,0.82)$ & 8.33 \\
\hline & Wu (2013) & $\quad 0.80(0.79,0.81)$ & 8.33 \\
\hline & You (2014) & $0.74(0.74,0.75)$ & 8.33 \\
\hline & Li (2017) & $0.66(0.66,0.67)$ & 8.33 \\
\hline & Matamoros (2015) & $0.39(0.39,0.39)$ & 8.33 \\
\hline & Dayan (2005) & $0.28(0.28,0.28)$ & 8.33 \\
\hline & Mcknight (2014) & $0.24(0.21,0.26)$ & 8.33 \\
\hline & Overall (I-squared $=100.0 \%, p=0.000$ ) & $0.70(0.49,0.90)$ & 100.00 \\
\hline & NOTE: Weights are from random effects analysis & & \\
\hline & -.967 & .967 & \\
\hline b & Study ID & $\mathrm{ES}(95 \% \mathrm{Cl})$ & Weight (\%) \\
\hline & Jung (2012) & $0.22(0.21,0.22)$ & 11.12 \\
\hline & Sun (2012) & $\rightarrow \quad 0.19(0.18,0.21)$ & 11.05 \\
\hline & $\operatorname{Lin}(2004)$ & $0.16(0.16,0.16)$ & 11.13 \\
\hline & Lee (2013) & $0.07(0.06,0.08)$ & 11.07 \\
\hline & Koh (2014) & $0.15(0.14,0.15)$ & 11.13 \\
\hline & Wu (2013) & $0.14(0.13,0.15)$ & 11.08 \\
\hline & You (2014) & $0.02(0.02,0.02)$ & 11.14 \\
\hline & Li (2017) & $0.07(0.06,0.07)$ & 11.14 \\
\hline & Matamoros (2015) & $0.03(0.03,0.04)$ & 11.14 \\
\hline & Overall (1-squared $=99.9 \%, p=0.000$ ) & $0.12(0.08,0.16)$ & 100.00 \\
\hline & NOTE: Weights are from random effects analysis & & \\
\hline & -.221 & .221 & \\
\hline
\end{tabular}

limitations should be acknowledged. First, cycloplegia was not used in our survey and it is well known that cycloplegic refraction yields better results than non-cycloplegic autorefraction. Non-cycloplegic autorefraction can result in overestimation of myopia [36]. However, because this was a large scale physical examination, cycloplegic refraction was difficult to apply in each subject due to limited resources. Second, questionnaires and face-to-face interviews were not applied in the study and we have no access to the demographic factors (e.g., race/ ethnicity/ genetic background/ socioeconomic status and so on). Therefore, only descriptive analysis was presented and no multivariate analysis to evaluate the risk factors that account for the increasing prevalence.

\section{Conclusion}

In conclusion, there was a remarkable increase in the prevalence of myopia among high school students in eastern China over the past 15 years, especially high and very high myopia. Females were more likely to develop myopia than males. More attention should be paid to prevention and control of myopia in the future, especially high and very high myopia.

\section{Additional file}

Additional file 1: Figure S1. A flow diagram detailing the selection of meta-analysis. Figure S2. Sensitivity analysis of myopia (A) and high myopia (B) prevalence. Sensitivity analysis by sequentially omitting individual studies did not alter the significance of pooled incidence 
estimates. Figure S3. Forest plot for included studies evaluating the prevalence of myopia (A, incidence $69.9,95 \% \mathrm{Cl}=49.5-90.3 \%, I^{2}=100 \%$ $P=0.000)$ and high myopia (B, incidence $11.6,95 \% \mathrm{Cl}=7.6-15.6 \%, \mathrm{I}^{2}=$ $99.9 \%, P=0.000$ ) in the random-effects model. (DOCX $148 \mathrm{~kb})$

\section{Abbreviations}

APC: annual percentage change; BCVA: best-corrected visual acuity; CAR: cycloplegic autorefraction; Cl: confidence interval; NCAR: noncycloplegic autorefraction; RE: refractive error; SER: spherical equivalent refraction; VA: visual acuity

\section{Acknowledgements}

The authors thank the Colleges of Ophthalmology department (Fenghua people's hospital) and the participants involved in this study as well as the schools where the research was conducted.

\section{Funding}

This study was supported by the National Natural Science Foundation of China (No.81700829) and the Fundamental Research Funds for the Central Universities.

\section{Availability of data and materials}

The datasets used and/or analyzed during the current study are available from the corresponding author on reasonable request.

\section{Authors' contributions}

M C, AM W and KJ W designed research; AM W and LN Z conducted research; M C and W W analyzed data; XY C and XN Y performed statistical analysis; M C and KJ W wrote the draft of the manuscript. All authors read, reviewed and approved the final manuscript.

\section{Ethics approval and consent to participate}

Ethical approval was obtained from the Medical College of Zhejiang University and Fenghua people's hospital Ethics Review Board. The study adhered to the tenets of the Declaration of Helsinki.

\section{Consent for publication}

Not applicable.

\section{Competing interests}

The authors declare that they have no competing interests.

\section{Publisher's Note}

Springer Nature remains neutral with regard to jurisdictional claims in published maps and institutional affiliations.

\section{Author details}

${ }^{1}$ Eye Center, the 2nd Affiliated Hospital, Medical College of Zhejiang University, Hangzhou, China. ${ }^{2}$ Zhejiang Provincial Key Lab of Ophthalmology, Hangzhou, China. ${ }^{3}$ Department of Ophthalmology, Fenghua People's Hospital, Fenghua, Zhejiang, China. ${ }^{4}$ Department of Ophthalmology, Lishui People's Hospital, Lishui, Zhejiang, China.

\section{Received: 24 January 2018 Accepted: 20 June 2018}

Published online: 03 July 2018

\section{References}

1. Morgan IG, Ohno-Matsui K, Saw SM. Myopia. Lancet. 2012;379(9827):1739-48.

2. Wong YL, Saw SM. Epidemiology of Pathologic myopia in Asia and worldwide. Asia Pac J Ophthalmol (Phila). 2016;5(6):394-402.

3. Morgan IG, He M, Rose KA. EPIDEMIC OF PATHOLOGIC MYOPIA: what can laboratory studies and epidemiology tell us? Retina. 2017:37(5):989-97.

4. Jung SK, Lee JH, Kakizaki H, Jee D. Prevalence of myopia and its association with body stature and educational level in 19-year-old male conscripts in Seoul, South Korea. Invest Ophthalmol Vis Sci. 2012;53(9):5579-83.

5. Lee YY, Lo CT, Sheu SJ, Lin JL. What factors are associated with myopia in young adults? A survey study in Taiwan military conscripts. Invest Ophthalmol Vis Sci. 2013;54(2):1026-33.

6. Sun J, Zhou J, Zhao P, Lian J, Zhu H, Zhou Y, Sun Y, Wang Y, Zhao L, Wei $Y$, Wang L, Cun B, Ge S, Fan X. High prevalence of myopia and high myopia in
5060 Chinese university students in shanghai. Invest Ophthalmol Vis Sci. 2012;53(12):7504-9.

7. Wu JF, Bi HS, Wang SM, Hu YY, Wu H, Sun W, Lu TL, Wang XR, Jonas JB. Refractive error, visual acuity and causes of vision loss in children in Shandong, China. The Shandong children eye study. PLoS One. 2013;8(12):e82763.

8. Bar Dayan Y, Levin A, Morad Y, Grotto I, Ben-David R, Goldberg A, Onn E, Avni I, Levi Y, Benyamini OG. The changing prevalence of myopia in young adults: a 13-year series of population-based prevalence surveys. Invest Ophthalmol Vis Sci. 2005:46(8):2760-5.

9. Vitale S, Sperduto RD, Ferris FL 3rd. Increased prevalence of myopia in the United States between 1971-1972 and 1999-2004. Arch Ophthalmol. 2009; 127(12):1632-9.

10. Holden BA, Fricke TR, Wilson DA, Jong M, Naidoo KS, Sankaridurg P, Wong TY, Naduvilath TJ, Resnikoff S. Global prevalence of myopia and high myopia and temporal trends from 2000 through 2050. Ophthalmology. 2016;123(5):1036-42

11. Ikuno Y. Overview of the complications of high myopia. Retina. 2017;37(12): 2347-51.

12. Leo SW. Scientific Bureau of World Society of Paediatric O, strabismus. Current approaches to myopia control Curr Opin Ophthalmol. 2017;28(3): 267-75

13. Hopf S, Pfeiffer N. Epidemiology of myopia. Ophthalmologe. 2017;114(1):20-3.

14. Koh V, Yang A, Saw SM, Chan YH, Lin ST, Tan MM, Tey F, Nah G, Ikram MK. Differences in prevalence of refractive errors in young Asian males in Singapore between 1996-1997 and 2009-2010. Ophthalmic Epidemiol. 2014; 21(4):247-55.

15. Yu X, Lyu D, Dong X, He J, Yao K. Hypertension and risk of cataract: a metaanalysis. PLoS One. 2014:9(12):e114012.

16. Higgins JP, Thompson SG, Deeks JJ, Altman DG. Measuring inconsistency in meta-analyses. BMJ. 2003:327(7414):557-60.

17. DerSimonian R, Kacker R. Random-effects model for meta-analysis of clinical trials: an update. Contemporary clinical trials. 2007:28(2):105-14.

18. Egger M, Davey Smith G, Schneider M, Minder C. Bias in meta-analysis detected by a simple, graphical test. BMJ. 1997:315(7109):629-34.

19. Begg CB, Mazumdar M. Operating characteristics of a rank correlation test for publication bias. Biometrics. 1994:50(4):1088-101.

20. Li N, Chen YL, Li J, Li LL, Jiang CZ, Zhou C, Liu CX, Li D, Gong TT, Wu QJ, Huang $\mathrm{YH}$. Decreasing prevalence and time trend of gastroschisis in 14 cities of Liaoning Province: 2006-2015. Sci Rep. 2016;6:33333.

21. Hankey BF, Ries LA, Kosary CL, Feuer EJ, Merrill RM, Clegg LX, Edwards BK. Partitioning linear trends in age-adjusted rates. Cancer Causes Control. 2000 11(1):31-5.

22. Xiang YB, Zhang W, Gao LF, Liu ZW, Xu WH, Liu EJ, Ji BT. Methods for time trend analysis of cancer incidence rates. Zhonghua Liu Xing Bing Xue Za Zhi. 2004:25(2):173-7.

23. Lin LL, Shih YF, Hsiao CK, Chen CJ. Prevalence of myopia in Taiwanese schoolchildren: 1983 to 2000. Ann Acad Med Singap. 2004:33(1):27-33.

24. Lee JH, Jee D, Kwon JW, Lee WK. Prevalence and risk factors for myopia in a rural Korean population. Invest Ophthalmol Vis Sci. 2013:54(8):5466-71.

25. Matamoros E, Ingrand P, Pelen F, Bentaleb Y, Weber M, Korobelnik JF, Souied E, Leveziel N. Prevalence of myopia in France: a cross-sectional analysis. Medicine (Baltimore). 2015;94(45):e1976.

26. Hrynchak PK, Mittelstaedt A, Machan CM, Bunn C, Irving EL. Increase in myopia prevalence in clinic-based populations across a century. Optom Vis Sci. 2013:90(11):1331-41.

27. McKnight CM, Sherwin JC, Yazar S, Forward H, Tan AX, Hewitt AW, Pennell CE, McAllister IL, Young TL, Coroneo MT, Mackey DA. Myopia in young adults is inversely related to an objective marker of ocular sun exposure: the western Australian Raine cohort study. Am J Ophthalmol. 2014;158(5):1079-85.

28. Vitale S, Ellwein L, Cotch MF, Ferris FL 3rd, Sperduto R. Prevalence of refractive error in the United States, 1999-2004. Arch Ophthalmol. 2008; 126(8):1111-9.

29. Li Y, Liu J, Qi P. The increasing prevalence of myopia in junior high school students in the Haidian District of Beijing, China: a 10-year population-based survey. BMC Ophthalmol. 2017;17(1):88

30. French AN, Ashby RS, Morgan IG, Rose KA. Time outdoors and the prevention of myopia. Exp Eye Res. 2013;114:58-68.

31. Ji CY, Chen TJ. Working group on obesity in C. Empirical changes in the prevalence of overweight and obesity among Chinese students from 1985 to 2010 and corresponding preventive strategies. Biomed Environ Sci. 2013; 26(1):1-12. 
32. Rose KA, Morgan IG, Smith W, Burlutsky G, Mitchell P, Saw SM. Myopia, lifestyle, and schooling in students of Chinese ethnicity in Singapore and Sydney. Arch Ophthalmol. 2008;126(4):527-30.

33. You QS, Wu L, Duan JL, Luo YX, Liu L, Li X, Gao Q, Wang W, Xu L, Jonas $J B$, Guo XH. Prevalence of myopia in school children in greater Beijing: the Beijing childhood eye study. Acta Ophthalmol. 2014;92(5):e398-406.

34. Guo YH, Lin HY, Lin LL, Cheng CY. Self-reported myopia in Taiwan: 2005 Taiwan National Health Interview Survey. Eye (Lond). 2012;26(5):684-9.

35. Ferraz FH, Corrente JE, Opromolla P, Padovani CR, Schellini SA. Refractive errors in a Brazilian population: age and sex distribution. Ophthalmic Physiol Opt. 2015:35(1):19-27.

36. Sanfilippo PG, Chu BS, Bigault O, Kearns LS, Boon MY, Young TL, Hammond $\mathrm{CJ}$, Hewitt AW, Mackey DA. What is the appropriate age cut-off for cycloplegia in refraction? Acta Ophthalmol. 2014;92(6):e458-62.

Ready to submit your research? Choose BMC and benefit from:

- fast, convenient online submission

- thorough peer review by experienced researchers in your field

- rapid publication on acceptance

- support for research data, including large and complex data types

- gold Open Access which fosters wider collaboration and increased citations

- maximum visibility for your research: over $100 \mathrm{M}$ website views per year

At BMC, research is always in progress.

Learn more biomedcentral.com/submissions 